\title{
The use of virtual patient scenarios as a vehicle for teaching professionalism
}

Citation for published version (APA):

Marei, H. F., Al-Eraky, M. M., Almasoud, N. N., Donkers, J., \& Van Merrienboer, J. J. G. (2018). The use of virtual patient scenarios as a vehicle for teaching professionalism. European Journal of Dental Education, 22(2), E253-E260. https://doi.org/10.1111/eje.12283

Document status and date:

Published: 01/05/2018

DOI:

10.1111/eje.12283

Document Version:

Publisher's PDF, also known as Version of record

Document license:

Taverne

Please check the document version of this publication:

- A submitted manuscript is the version of the article upon submission and before peer-review. There can be important differences between the submitted version and the official published version of record.

People interested in the research are advised to contact the author for the final version of the publication, or visit the DOI to the publisher's website.

- The final author version and the galley proof are versions of the publication after peer review.

- The final published version features the final layout of the paper including the volume, issue and page numbers.

Link to publication

\footnotetext{
General rights rights.

- You may freely distribute the URL identifying the publication in the public portal. please follow below link for the End User Agreement:

www.umlib.nl/taverne-license

Take down policy

If you believe that this document breaches copyright please contact us at:

repository@maastrichtuniversity.nl

providing details and we will investigate your claim.
}

Copyright and moral rights for the publications made accessible in the public portal are retained by the authors and/or other copyright owners and it is a condition of accessing publications that users recognise and abide by the legal requirements associated with these

- Users may download and print one copy of any publication from the public portal for the purpose of private study or research.

- You may not further distribute the material or use it for any profit-making activity or commercial gain

If the publication is distributed under the terms of Article $25 \mathrm{fa}$ of the Dutch Copyright Act, indicated by the "Taverne" license above, 


\title{
The use of virtual patient scenarios as a vehicle for teaching professionalism
}

\author{
H. F. Marei ${ }^{1,2}$ (1) | M. M. Al-Eraky ${ }^{3,4}$ | N. N. Almasoud ${ }^{1}$ | J. Donkers ${ }^{5}$ | \\ J. J. G. Van Merrienboer ${ }^{5}$
}

${ }^{1}$ College of Dentistry, University of Dammam, Dammam, Saudi Arabia

${ }^{2}$ Faculty of Dentistry, Suez Canal University, Ismailia, Egypt

${ }^{3}$ Directorate for Development and Academic Initiatives, University of Dammam, Dammam, Saudi Arabia

${ }^{4}$ Faculty of Medicine, Zagazig University, Zagazig, Egypt

${ }^{5}$ School of Health Professions Education, Maastricht University, Maastricht,

Netherlands

\section{Correspondence}

Hesham F. Marei, College of Dentistry,

University of Dammam, Dammam, Saudi

Arabia.

Emails: hmarei@uod.edu.sa;

hesham.marei@yahoo.com

Funding information

Deanship of Scientific Research, University of

Dammam, Grant/Award Number: 2015038

\begin{abstract}
Objectives: This study aimed to measure students' perceptions of virtual patient scenarios (VPs) for developing ethical reasoning skills and to explore features in VP design that are necessary to promote professionalism.

Methods: Sixty-five dental students participated in learning sessions that involved collaborative practice with five VPs (four high fidelity and one low fidelity), followed by reflection sessions. Students' perceptions towards the use of VPs in developing ethical reasoning skills were assessed using a questionnaire that involved 10 closed and three open-ended questions.

Results: High-fidelity VPs were perceived as significantly better for developing ethical reasoning skills than low-fidelity VPs. Analyses of answers to open-ended questions revealed two new features that are specific for VPs intended for teaching professionalism, which are VP dramatic structure and how it should end.

Conclusion: VPs intended for teaching professionalism need to have high fidelity, follow a specific dramatic structure and should include multiple plausible endings. The use of VPs as part of a collaborative activity that is followed by a reflection session is perceived as an effective tool for the development of ethical reasoning skills in dental education.
\end{abstract}

KEYWORDS

ethical reasoning, professionalism, virtual patient, virtual simulation

\section{1 | INTRODUCTION}

Professionalism is an essential competency that must be demonstrated by healthcare graduates. Unprofessional behaviour of students during medical schools is correlated with disciplinary action amongst practicing physicians during working life. ${ }^{1}$ In the same vein, analysis of medical litigations in dental practice showed that the majority of lawsuits was filed due to unprofessional conduct, such as violation in the scope of practice, negligence during the consenting process, lack of respect to patients' choices and absence of support to patients when complications arise. ${ }^{2,3}$ Therefore, the Association of Dental Education in Europe recommended that dental schools should put strategies into place for teaching professionalism, and referred to simulation as one of the teaching methods that can be used for reaching this goal. ${ }^{4}$

Simulation varies in its complexity and ability to represent real patient situations. It could be in the form of physical simulation such as a mannequin head for training students on local anaesthetic injection, teeth extraction and cavity preparation., ${ }^{5,6}$ Computer software programs are other tools that are used for simulating the clinical encounter, patients' problems and/or the consequences of the decision taken by the learner. ${ }^{7-9}$ Furthermore, simulation could involve recruiting standardised and/or simulated patients (SP) for teaching and assessing students' skills in history taking, breaking bad news and obtaining an informed consent. ${ }^{10}$ However, the costly process of recruitment, 
selection and retention of suitable and credible SP is critical to running a SP programme. ${ }^{11}$

One of the currently available forms of computer simulation is provided by virtual patient scenarios (VPs). These are computer simulations of real-life clinical scenarios that have been used effectively for enhancing knowledge retention ${ }^{12}$ and for teaching clinical reasoning skills. ${ }^{7,13}$ The use of VPs has been perceived well by students in various medical and dental studies, ${ }^{8,14}$ because they offer students the opportunity to take decisions in a safe environment and to contemplate consequences of their actions as if they are doctors in charge. ${ }^{13,15}$

Different studies that investigated learners' perceptions towards VPs showed that learners prefer specific features in VP design such as realism, relevance, appropriate level of difficulty, high interactivity and feedback. ${ }^{13,15}$ Although VPs have been used in different contexts, little seems to be known about their potential for teaching professionalism in health professions education and whether their use in teaching professionalism requires specific design features.

Teaching professionalism is challenging for many reasons. There is no conclusive definition of professionalism. ${ }^{16-18}$ Most professionalism dilemmas do not have a clear-cut between correct and wrong answers. ${ }^{19}$ In learning professionalism, students are confronted with different plausible options for decision-making, and they need to learn ethical reasoning skills. The variety of options might dictate specific features in VP design to accommodate the complexity of professionalism dilemmas. Furthermore, professionalism needs to be understood and interpreted in view of the social contract, ${ }^{20}$ which means VPs that have been designed for a specific context may not work in a different context or culture.

Professionalism is culture-specific. Western frameworks on professionalism were found inappropriate to other context, which drives researchers to embrace other cultural perspectives on the attributes and behaviours of health professionals. ${ }^{21,22}$ Some of the universally acknowledged humanistic attributes are respect, excellence (aspiring to perfection), confidentiality, accountability and honesty. ${ }^{21,23,24}$ The progress in operationalising the professionalism concept into workable attributes and behaviours unlocked the gate for clinical teachers in different cultures to plan what they should teach and therefore think about how to use the currently available instructional methods in teaching the underlying cognitive base and developing the required attributes.

Situated learning theory was described by Birden et al. ${ }^{25}$ as the most relevant model that can be followed for developing and designing instructions towards teaching professionalism. The theory argues that learning occurs as a result of a complex interaction between the participants (social context), their environment (physical context) and authentic activities that are led by a mentor or teacher. ${ }^{26}$ In the same vein, role modelling in a clinical context, where there is interaction between dentists, patients and nurses in situations creating real dilemmas, was considered as an effective method in teaching professionalism. ${ }^{25}$ However, standardisation of clinical rotations across the wide spectrum of patients, tutors and colleagues poses a challenge for educators. Moreover, the medical profession has a wide range of roles and practices in systems that put great limits on personal autonomy, making role modelling problematic. $^{27}$
This problem has resulted in teachers using conventional teaching methods such as lectures in conveying the intended messages, which are usually in the form of "DOs and DON'Ts". ${ }^{28}$ Others used problems and writing exercises to stimulate students' reflection, ${ }^{29}$ but still such practice may result in isolation of the cognitive base of professionalism from clinical practice, which could make the acquired knowledge difficult to transfer to the workplace. Therefore, simulation might better help learners to internalise the cognitive base of professionalism by allowing them to situate it within the clinical context. ${ }^{19}$

In a recent study, Hooper et al. ${ }^{30}$ mentioned that $85 \%$ of students perceived VPs as an effective way for gaining knowledge relevant to medical ethics, but still more research is required to find out its potential in ethical reasoning and decision-making skills. ${ }^{31}$ To the best of our knowledge, there is no existing evaluation instrument that is designed specifically for measuring the perception of using VPs in developing ethical reasoning skills. However, Huwendiek and de Leng ${ }^{32}$ have developed and used a questionnaire assessing students' experiences with VPs for learning clinical reasoning skills. The development of this questionnaire was based on literature about strategies to teach clinical reasoning, the design of teaching cases and the results of a focus group study exploring students' perceptions of the ideal design of VPs for learning clinical reasoning skills.

Currently, there are different ways for using VPs within the classroom. ${ }^{33}$ However, situated learning theory resonates well with the latest paradigm shift from independent learning using VPs to integrating VPs in whole learning activities such as a VP collaborative learning activity. In such activity, learners work in groups with the virtual patient, discussing their options at each step and reaching consensus on what their collective action will be. Therefore, the VP in such an activity acts mainly as a trigger for students' discussion and debate. Learning would depend on students' interactions with each other more than their direct interaction with the VP itself. ${ }^{33}$ That said, the collaborative work of students (social context) with VPs based on authentic professionalism dilemmas, followed by a reflection session guided by faculty, could be an effective method for developing ethical reasoning skills that are required in decision-making on professionalism dilemma. Moreover, a collaborative learning activity could also fulfil two main requirements that are proposed for teaching professionalism: creating learning opportunities that are appropriate to the level of the learners and allowing structured time for guided reflection. ${ }^{34}$ Guided reflection in such a context might enable students to discuss with their faculty the suboptimal answers. On the other hand, the faculty would be able to investigate why specific answers have been chosen and why the other options are not correct.

The physical environment of these learning activities is actually formed by the classroom and the VPs, so it is not as situated as in the clinical setting and real patients. Therefore, this study investigates how using VPs in the classroom can help students in developing their ethical reasoning skills, and what are the VP design features that learners perceive as crucial for teaching professionalism? 


\section{2 | METHODS}

\section{1 | Participants}

Sixty-seven students who were registered in an oral and maxillofacial surgery course for the academic year 2015/2016 (2nd semester) agreed to participate in the study. All students were in their 5 th academic year of a 6-year discipline-based dental programme. Two students did not attend the learning sessions in the study; therefore, the total number of participants was 65 students $(\mathrm{N}=65)$ in two main groups: males $(n=36)$ and females $(n=29)$. Each main group of students was divided into small groups of five to six students each.

\section{2 | Materials}

\subsection{1 | Classroom}

The classroom contains six interactive multitouch tables that are connected to 5-6 headphones to allow the students in the small groups to listen to the different VPs without having a sound collision from the neighbouring table, whilst during discussion, students can take the headphone off so they can listen to each other.

\subsection{2 | Virtual Patients}

The study involved the use of five virtual patients, tackling four professionalism dilemmas, namely privacy, confidentiality, excellence (aspiring to perfection) and honesty (Table 1). The virtual patients were different in their physical fidelity levels as four VPs (VP 1, 2, 4, 5) had a high-fidelity design, in which two-dimensional graphics were used to represent different clinical settings and different characters within the VPs (Figure 1). Real human photographs with a real human sound were used to project the different characters in the VPs. The VPs display real patient radiographs, laboratory results, intra-oral photographs and records for other special investigations at different stages of VPs path. VP 3 has low fidelity and presents the storyboard of the clinical scenario in a text format using PowerPoint. The PowerPoint slides are hyperlinked to each other in order to allow the students to follow the consequences of the decisions taken; therefore, both designs have the same functional fidelity, which is how they respond to students' choices.

\subsection{3 | Measuring instruments}

A questionnaire that was developed by Huwendiek and de Leng ${ }^{32}$ for measuring students' perceptions of the development of clinical reasoning skills was adapted for this study. The reliability of different subscales of the original questionnaire ranged from 0.74 to $0.82 .{ }^{35}$
The questionnaire is adapted by paraphrasing items to address perception of ethical reasoning using high- and low-fidelity VPs (for instance item number 1: whilst working on this case, I felt I had to make the same decisions a doctor would make in real life is paraphrased to Which of these virtual patients, you had the same decisions a doctor would make in real life?).

The adapted questionnaire contained 10 closed and three openended questions (Table 2). The questions clustered into five main categories, which are the authenticity of the patient encounter, professional approach in consultation, coaching during consultation, learning effect and overall judgement. For the closed questions, the students were asked to rank the five VPs from 1 to 5 ; in which 1 is the best VP and 5 is the worse VP. The open-ended questions required the students to reflect on special strengths and weaknesses regarding VP designs and to comment on the overall learning session. All the students filled the questionnaire immediately after the learning session.

\section{3 | Procedure}

The study involved two identical sessions, one for male and one for female students. Both sessions were conducted in the same classroom, used the same VPs and were facilitated by the same two faculty members, but at different points in time. Every learning session lasted for almost three hours and involved three parts: introduction, VP collaborative practice and reflection.

\subsection{1 | Introduction}

Lasted 10 minutes, in which an overview was provided about the VPs and how they respond to students' selections of different options. It involved also assigning a leader to every small group. He or she would operate the touch screen after the whole group discussed together the different questions and choices in the VP path.

\subsection{2 | VP collaborative practice}

Lasted for nearly one hour, all students practiced the five VPs simultaneously in small groups (five to six students each). During collaborative practice, the students listened, watched and then discussed together in groups before taking a collective decision in different VPs. Two faculty members were moving between the tables to observe students' practice and respond to any questions.

\subsection{3 | Reflection part}

Two faculty members facilitated five reflection periods (one after each VP). Each reflection period lasted for about 20 minutes and was

TABLE 1 The five VPs per topic and fidelity

\begin{tabular}{|llllll} 
VP & VP1 & VP2 & VP3 & VP4 & VP5 \\
\hline Topic & Privacy & Confidentiality & Confidentiality & Excellence & Honesty \\
Fidelity & High & High & Low & High & High \\
\hline
\end{tabular}




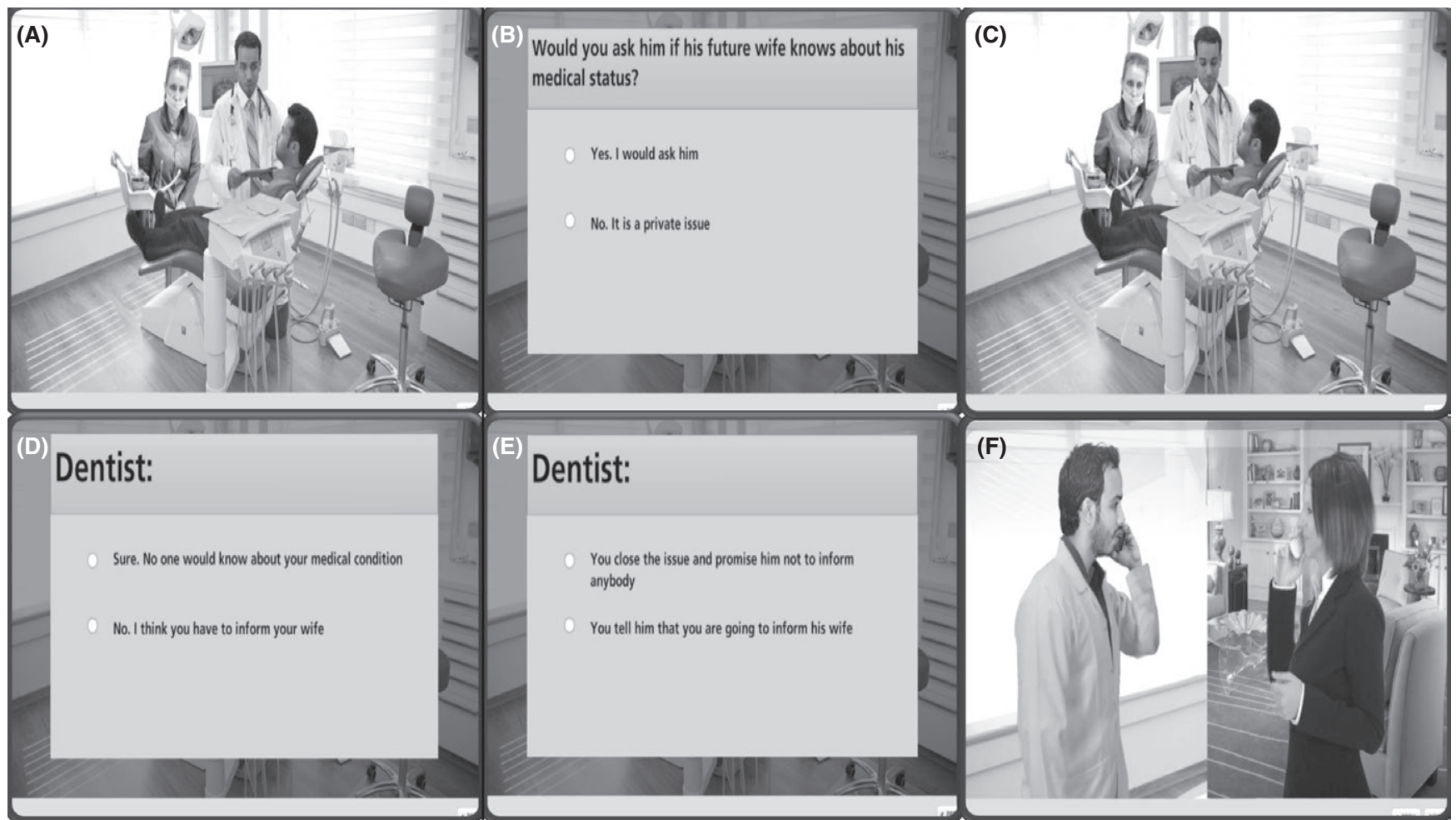

FIGURE 1 Multiple screenshots from VP2. The learner takes the role of the dentist in dealing with a patient with hepatitis C virus. The patient is going to get married to a lady who had wisdom teeth taken out within the same dental office. The ethical dilemma is about breaching the confidentiality of patient information if a third party could be at risk. (A) Dentist takes full medical and dental history, (B) The VP branches based on learner selection, (C) The dentist is asking the patient if his future wife knows about his medical status based on learner selection in the previous screen, (D, E) The VP branches based on the learner selection, (F) The patient wife phoned the dentist telling him that she is aware of the medical condition of her future husband because the learner decided to enforce the patient to inform his future wife

based on seven pre-defined questions that were used as triggers for reflection on professionalism dilemmas ${ }^{36}$ (Table 3). Furthermore, students were allowed to provide their opinion on the different characters and to describe any relevance to previous experiences with real patients.

\subsection{Data collection and analysis}

The college's statistical unit collected the filled questionnaires. The quantitative data were analysed using SPSS Software (SPSS 22.0, SPSS Inc., Chicago, IL, USA). ANOVA was used to find any significant differences between the low-fidelity and high-fidelity VPs. Post hoc Tukey HSD was performed for multiple pairwise comparisons. The $P$-value for statistical significance was set at $5 \%$.

Thematic analysis was generated based on students' qualitative data (open-ended questions) using Excel. We followed the conventional approach to content analysis. The response from each student was considered the unit of analysis. Meaning units represented features of ideal VP design and varied in length, ranging from one word, for example "realism" and "interactivity" to one or multiple statements, for example "I want to see a VP that is similar to a movie". Short meaning units were condensed and coded as such, but longer ones were shortened with the preservation of their gist to form condensed meaning units. One code was given to them. Codes were then grouped under higher headings (categories), which were eventually clustered in themes.

\section{5 | ETHICAL APPROVAL}

The study was reviewed and approved by the University Ethical Committee (IRB number: 2015-02-099), and all participants gave informed consent before the beginning of the study. It was clearly announced that the session is optional, and students' attendance does not contribute to their grades or evaluation.

\section{3 | RESULTS}

All participants $(\mathrm{N}=65)$ filled out the questionnaire. The mean rating scores for the high-fidelity VPs were $31.9 \pm 7.5$ for VP1, 32.9 \pm 8.0 for VP2, 32.6 \pm 6.8 for VP4 and $31.4 \pm 8.2$ for VP5, whilst for the low-fidelity VP (VP3), it was $27.2 \pm 8.0$ (Table 4). Reliability statistics showed a Cronbach's alpha of 0.75 for the 10 items.

For the influence of different designs on students' perceptions of ethical reasoning, there was a significant difference between the five VPs, $F(1,65)=5.47, P=.00$. Tukey HSD showed that the main difference was between VP 3 (low-fidelity design) and VP1, VP2, VP4 and VP5, as the mean of any of the high-fidelity VPs was higher than the 
TABLE 2 The measuring instrument (Questionnaire)

\begin{tabular}{|c|c|c|c|c|c|c|}
\hline No. & Question & VP1 & VP2 & VP3 & VP4 & VP5 \\
\hline 1 & Which of these virtual patients, you had the same decisions a doctor would make in real life? & & & & & \\
\hline 2 & Which of these virtual patients, you felt you were really the doctor caring for this patient? & & & & & \\
\hline 3 & $\begin{array}{l}\text { Which one was informative enough and you were aware of the required patient information } \\
\text { (e.g., history questions, clinical exams, lab tests) to characterize the ethical dilemma? }\end{array}$ & & & & & \\
\hline 4 & Which of these virtual patients, you were able to easily indicate the ethical dilemma? & & & & & \\
\hline 5 & $\begin{array}{l}\text { Which one you were actively engaged in thinking about which findings supported or refuted } \\
\text { your decision? }\end{array}$ & & & & & \\
\hline 6 & Which one was at the appropriate level of difficulty for your training? & & & & & \\
\hline 7 & Which of these virtual patients enhanced your ethical reasoning skills? & & & & & \\
\hline 8 & Which one provides better feedback for your reasoning? & & & & & \\
\hline 9 & $\begin{array}{l}\text { Which of these virtual patients made you feel better prepared to deal with similar real patients } \\
\text { in your future practice? }\end{array}$ & & & & & \\
\hline 10 & Which one you think it was a worthwhile learning experience? & & & & & \\
\hline 11 & Special Strengths in VP design and activity? & & & & & \\
\hline 12 & Special weaknesses in VP design and activity? & & & & & \\
\hline 13 & Additional comments and suggestions in regard to the whole activity? & & & & & \\
\hline
\end{tabular}

TABLE 3 Triggers/questions to guide reflection on professionalism dilemmas

\begin{tabular}{ll}
\hline 1 & Describe your feelings, if you were in that situation. \\
\hline 2 & $\begin{array}{c}\text { What is the professionalism dilemma of the given } \\
\text { scenario? }\end{array}$ \\
\hline 3 & What would you do in that situation? and why? \\
\hline 5 & What are the expected consequences of your decision? \\
\hline 6 & $\begin{array}{c}\text { What if you were in the shoes of the colleague or the } \\
\text { patient? (Swapping roles) }\end{array}$ \\
\hline 7 & $\begin{array}{l}\text { What did you learn from discussing this scenario? } \\
\text { Do you feel more prepared in case if you encounter a }\end{array}$ \\
\hline
\end{tabular}

low-fidelity VP $(P=.007, .001, .001$ and .023 , respectively). There was no significant difference between the different high-fidelity VPs in pairwise comparison. Furthermore, there was no significant difference between learning perception of male and female students for the different VPs.

Analysis of students' responses to open questions showed three main themes with nine categories as shown in Table 5. The main findings that were extracted from students' responses confirmed that the use of VPs was perceived as an effective tool in learning ethical reasoning skills (eg "I think I can weigh between different decisions"). However, the use of audio-visual effects was considered as a crucial element in VP design (eg "The audiovisual effects have added more reality to the VP"). The students acknowledged the reality of the problems that they encountered (eg "The problems that we have experienced were very real"), and preferred to see the arrangement of events in the VP similar to that seen in a movie (eg "I want to see a VP that is similar to a movie"). They have also requested to have links inside the VP to rules, regulation and reference materials that are relevant to the encountered problem (eg "We need to have links to rules and regulations in our country"). Furthermore, they considered group practice and having a reflection session as key elements during VP implementation (eg "The feedback session was as important as practicing with the VPs").

\section{4 | DISCUSSION}

The current study measured the perception of students' towards five VPs that targeted ethical reasoning skills and explored features in VP design that make VPs suitable for teaching and learning professionalism in dental education.

The study showed that VPs with high fidelity were perceived as significantly better for developing ethical reasoning skills than the one with low-fidelity design. Although all the designs were similar in their functional fidelity, which is how the VP responds to students' choices, still the appearance of the different characters, their sound and the projection of the clinical setting had a great impact on students' perceptions. Our students' preferences were consistent with students' preferences in previous studies, ${ }^{13,15}$ which showed that students prefer VPs that are interactive, rich in media, authentic, have appropriate difficulty and are based on real-life scenarios relevant to their future practice.

Although students' preference is crucial in designing specific instructional methods to make learning enjoyable and attractive to them, still the preferred way of learning does not need to be the most effective way of learning. ${ }^{37}$ Moreover, learner preference for selecting particular instructional methods could be uncorrelated or negatively correlated to learning outcomes. ${ }^{38}$ Therefore, students' preference of high-fidelity VPs is only one aspect of evaluation, which stands at the first level of Kirkpatrick model, whilst the other aspect would be evaluation of students' actual performance and learning outcomes 


\begin{tabular}{|lccccc|} 
& VP1 & VP2 & VP3 & \multicolumn{1}{l}{ VP4 } & \multicolumn{1}{l|}{ VP5 } \\
\hline Mean \pm SD & $31.9 \pm 7.5$ & $32.9 \pm 8.0$ & $27.2 \pm 8.0$ & $32.6 \pm 6.8$ & $31.4 \pm 8.2$ \\
\hline VP 3 & $P=.007$ & $P=.001$ & - & $P=.001$ & $P=.023$ \\
\hline
\end{tabular}

TABLE 4 Mean, standard deviation and pairwise comparison between high- and low-fidelity VPs

$P$-value for statistical significance was set at $5 \%$.

TABLE 5 Synopsis of themes, categories and examples of students' input

\begin{tabular}{|c|c|c|}
\hline Theme & Categories & Citations of students' answers to open questions \\
\hline \multirow{4}{*}{ Design } & Storyboard & $\begin{array}{l}\text { - I liked the VPs because it enhanced the discussion about right and wrong decisions } \\
\text { - I want to see a VP that is similar to a movie } \\
\text { - I will not forget that I have been taken to the court at the end of the VP } \\
\text { - Unforgettable experience as my stress went up while I am taking some difficult decisions. } \\
\text { - Some problems could have two correct answers at the end of the VP } \\
\text { - Being not sure about the answer increased my engagement }\end{array}$ \\
\hline & $\begin{array}{l}\text { Difficulty of the } \\
\text { content }\end{array}$ & $\begin{array}{l}\text { - It was at a good level of understanding } \\
\text { - The VPs were clear }\end{array}$ \\
\hline & Interactivity & $\begin{array}{l}\text { - Very entertaining and interactive } \\
\text { - VP responding to my choices was good }\end{array}$ \\
\hline & $\begin{array}{l}\text { Link to external } \\
\text { resources }\end{array}$ & $\begin{array}{l}\text { - I would expect to have links to reference materials relevant to the problems } \\
\text { - We need to have links to rules and regulations in our country }\end{array}$ \\
\hline \multirow[t]{2}{*}{ Implementation } & Practice & $\begin{array}{l}\text { - Group practice were very helpful } \\
\text { - I liked thinking together in a group } \\
\text { - The available resources facilitated working as a group }\end{array}$ \\
\hline & Reflection & $\begin{array}{l}\text { - The feedback session was as important as practicing with the VPs } \\
\text { - Discussion in the feedback sessions resolved all my inquires } \\
\text { - The feedback sessions added to my ability to take correct decisions } \\
\text { - I was not sure about the most appropriate answer in some VP till the reflection session }\end{array}$ \\
\hline Learning & Ethical reasoning & $\begin{array}{l}\text { - I think I can weigh between different decisions } \\
\text { - Now I can think more in depth in ethical dilemmas } \\
\text { - The VP let me think like a dentist }\end{array}$ \\
\hline
\end{tabular}

(second level of Kirkpatrick model), which was not within the scope of our study.

Two features in the VP design theme have emerged in our study and were not mentioned by students in previous VP studies. The first is the dramatic structure that is relevant to the storyboard. Students have commented on the necessity of building and arranging the incidents in the VP storyboard as in the movies. Furthermore, they said it is important to extend the uncertainty about the correct answer to increase engagement in the VP. Students' views are consistent with what Reeve $^{39}$ advocated in developing serious games. This author stated that a good story is recognised as a highly efficient motivator for the learners. A good narrative gives a game a level of sophistication that promotes greater engagement and encourages longer involvement. The emotional attachment manifests itself in the desire to know what would happen if a specific option is selected. Therefore, it is crucial to maintain the correct mix between storytelling and the free exploratory activity in order to keep the learner actions as a part of the story.
In real moviemaking, it is stated that the arrangement of the incidents that take place in a dramatic work such as a play or film should pass through different stages namely exposition, conflict, rising action, climax, falling action and resolution. ${ }^{40}$ Although watching a movie is different from practicing a VP that requires active participation from the learners, still based on students' perception, building the storyboard to pass through the different movie stages could be possible. Exposition could be achieved by introducing the main characters in the VP during history taking; conflict can be presented through questions that are relevant to the professionalism dilemma; rising action till climax can be projected by directing the students (based on their choices) to different screens that complicate the dilemma; and finally, falling action and resolution could be fulfilled by the reflection session, in which the students discuss the advantages and disadvantages of every decision and what would support one decision over the others.

The second feature is how VPs should end. In general, VPs have either one end node, or multiple end nodes. In the first design, the VP branches 
or not based on learners' decisions to end in one end node. The second is more complex in branching and involves multiple end nodes. One of them represents the correct pathway that should be taken, whilst the other nodes represent the different consequences of wrong decisions. ${ }^{41}$

Transferring these designs to complex professionalism dilemmas might require the VP to end with multiple correct end nodes because the real world contains situations that are complex enough to end with multiple correct answers. Sternszus ${ }^{19}$ stated that students do not need to understand medical professionalism in order to know how to react to scenarios that have clear right and wrong answers, and such simple scenarios might make the students disengage from professionalism education. Furthermore, it was indicated that it is important to put all the efforts that promote positive professional behaviour rather than providing curricula that focus on ensuring that the students do not behave unprofessionally. ${ }^{19,34}$ Although such design may create a form of uncertainty amongst students because they are used to one correct answer, their doubt can be resolved during the reflection session that should not be separated from the VP activity.

In regard to the VP implementation, students acknowledged that collaborative practice was conductive to learning. Such perception may be due to two main reasons. One is relevant to the scenario, which involved challenging questions that have highly plausible options; therefore, students had to go in intense discussions to agree on a specific answer. Second, the student arrangements in 5-6 participants around the interactive tables have facilitated their discussion. Our results are consistent with Ellaway et al.'s study, ${ }^{33}$ who stated that in VP collaborative activities, much of the learning value is generated by the discussion and debate rather than by direct interactions with the VP.

The second feature that is relevant to VP implementation is the reflection sessions. The students have recognised them as important as the VP practice. The reflection session prepared students to deal with uncertainty, as we asked them to acknowledge the complexity of reallife situations and embrace more than one plausible option based on many variables. Second, the facilitator's negotiation of the students' answer opened the students' mind to new perspectives so they were able to see the whole picture. We advocate that the aim of such reflection session is not to dictate or enforce specific answers, but to teach the students how to think and react to future similar dilemmas if some of the data have changed. We consider reflection as a central part of VP practice sessions. It allows students to analyse, question and reframe (real or simulated) experiences to make an assessment of it for the purposes of learning (reflective learning) and/or to improve practice (reflective practice). ${ }^{42}$ Furthermore, authors advocated that teaching professionalism in general (without VP) requires structured time for guided reflection. ${ }^{34,36}$

This study is not without limitations. It measured the perception for learning ethical reasoning skills, whilst there is a need to objectively assess students' abilities for reasoning skills after using VPs. Also there is a wide spectrum of VP designs that needed to be explored in relation to ethical reasoning skills and professionalism. The VP can be further used in different integration models such as a stand-alone or as a blended activity, not only as a collaborative learning activity. The study has provided two main practical implications. First, the design of VPs that are intended for developing professionalism should be centred on a well-written storyboard that follows a recognised dramatic structure. Second, the VPs should be designed to have multiple correct end nodes to enhance positive professional behaviour.

\section{5 | CONCLUSION}

VPs that are intended for teaching professionalism need to have high fidelity, follow a specific dramatic structure and should include multiple plausible endings. The use of VPs as a part of a collaborative activity that is followed by a reflection session has been perceived as an effective tool for developing ethical reasoning skills in dental education.

\section{ACKNOWLEDGEMENT}

This work was supported by a grant from the Deanship of Scientific Research, University of Dammam, Saudi Arabia (Project no. 2015038). The authors would like to thank Dr. Bandar Al-Amer and his team for facilitating the use of classrooms at the Deanship of E-learning.

\section{CONFLICT OF INTEREST}

We the authors of this work declare that we have no dual commitment or any possible conflict of interest at the time of submission. These include any financial interests.

\section{ETHICAL APPROVAL}

We confirm that the ethical committee of our institute has approved this work, and it is in agreement with the guidelines of the Helsinki Declaration as revised in 1975.

\section{REFERENCES}

1. Papadakis MA, Teherani A, Banach MA, et al. Disciplinary action by medical boards and prior behavior in medical school. N Engl J Med. 2005;353:2673-2682.

2. Marei HF. Medical litigation in oral surgery practice: lessons learned from 20 lawsuits. J Forensic Leg Med. 2013;20:223-225.

3. Krause HR, Bremerich A, Rustemeyer J. Reasons for patients' discontent and litigation. J Craniomaxillofac Surg. 2001;29:181-183.

4. Manogue M, McLoughlin J, Christersson C, et al. Curriculum structure, content, learning and assessment in European undergraduate dental education - update 2010. Eur J Dent Educ. 2011;15: 133-141.

5. Marei HF, Al-Jandan BA. Simulation-based local anaesthesia teaching enhances learning outcomes. Eur J Dent Educ. 2013;17:e44-e48.

6. Perry S, Bridges SM, Burrow MF. A review of the use of simulation in dental education. Simul Healthc. 2015;10:31-37.

7. Cook DA, Triola MM. Virtual patients: a critical literature review and proposed next steps. Med Educ. 2009;43:303-311.

8. Schittek Janda M, Mattheos N, Nattestad A, et al. Simulation of patient encounters using a virtual patient in periodontology instruction of dental students: design, usability, and learning effect in historytaking skills. Eur J Dent Educ. 2004;8:111-119.

9. Zary N, Johnson G, Fors U. Web-based virtual patients in dentistry: factors influencing the use of cases in the Web-SP system. Eur J Dent Educ. 2009;13:2-9. 
10. Carey JA, Madill A, Manogue M. Communications skills in dental education: a systematic research review. Eur J Dent Educ. 2010;14:69-78.

11. Cleland JA, Abe K, Rethans JJ. The use of simulated patients in medical education: AMEE guide no 42. Med Teach. 2009;31:477-486.

12. Botezatu M, Hult $\mathrm{H}$, Tessma MK, Fors U. Virtual patient simulation: knowledge gain or knowledge loss? Med Teach. 2010;32:562-568.

13. Huwendiek S, Reichert F, Bosse HM, et al. Design principles for virtual patients: a focus group study among students. Med Educ. 2009;43:580-588.

14. Botezatu M, Hult H, Kassaye Tessma M, Fors UG. As time goes by: stakeholder opinions on the implementation and use of a virtual patient simulation system. Med Teach. 2010;32:e509-e516.

15. Botezatu M, Hult H, Fors UG. Virtual patient simulation: what do students make of it? A focus group study. BMC Med Educ. 2010;10:91.

16. Zijlstra-Shaw S, Robinson PG, Roberts T. Assessing professionalism within dental education; the need for a definition. Eur J Dent Educ. 2012;16:e128-e136.

17. Birden H, Glass N, Wilson I, Harrison M, Usherwood T, Nass D. Defining professionalism in medical education: a systematic review. Med Teach. 2014;36:47-61.

18. Trathen A, Gallagher JE. Dental professionalism: definitions and debate. Br Dent J. 2009;206:249-253.

19. Sternszus R. Developing a professional identity: a learner's perspective. In: Cruess RL, Cruess SR, Steinert Y, eds. Proceedings of the Teaching Medical Professionalism: Supporting the Development of a Professional Identity. Cambridge, UK: Cambridge University Press; 2016:26-33.

20. Cruess RL, Cruess SR. Teaching professionalism: general principles. Med Teach. 2006;28:205-208.

21. Al-Eraky MM, Donkers J, Wajid G, van Merrienboer JJ. A Delphi study of medical professionalism in Arabian countries: the Four-Gates model. Med Teach. 2014;36(Suppl 1):S8-S16.

22. Tsai TC, Lin CH, Harasym PH, Violato C. Students' perception on medical professionalism: the psychometric perspective. Med Teach. 2007; 29:128-134.

23. Hilton SR, Slotnick HB. Proto-professionalism: how professionalisation occurs across the continuum of medical education. Med Educ. 2005;39:58-65.

24. Steinert Y, Cruess RL, Cruess SR, Boudreau JD, Fuks A. Faculty development as an instrument of change: a case study on teaching professionalism. Acad Med. 2007;82:1057-1064.

25. Birden H, Glass N, Wilson I, Harrison M, Usherwood T, Nass D. Teaching professionalism in medical education: a best evidence medical education (BEME) systematic review. BEME guide no. 25. Med Teach. 2013;35:e1252-e1266.

26. Durning SJ, Artino AR. Situativity theory: a perspective on how participants and the environment can interact: AMEE guide no. 52. Med Teach. 2011;33:188-199.
27. Cruess RL. Teaching professionalism: theory, principles, and practices. Clin Orthop Relat Res. 2006;449:177-185.

28. Field J, Ellis J, Abbas C, Germain P. Teaching and assessment of professional attitudes in UK dental schools - commentary. Eur J Dent Educ. 2010;14:133-135.

29. Lantz MS, Bebeau MJ, Zarkowski P. The status of ethics teaching and learning in U.S. dental schools. J Dent Educ. 2011;75:1295-1309.

30. Hooper CR, Jivram T, Law S, Michell A, Somasunderam A. Using virtual patients to teach medical ethics, medical law and medical professionalism. Med Teach. 2012;34:674-675.

31. Hooper C. Ethics virtual patients: a new pedagogical tool for educators? J Med Ethics. 2015;41:549-552.

32. Huwendiek S, de Leng BA. Virtual patient design and curricular integration evaluation toolkit. Med Educ. 2010;44:519.

33. Ellaway R, Topps D, Lee S, Armson H. Virtual patient activity patterns for clinical learning. Clin Teach. 2015;12:267-271.

34. Al-Eraky MM. Twelve tips for teaching medical professionalism at all levels of medical education. Med Teach. 2015;37:1018-1025.

35. Huwendiek S, De Leng BA, Kononowicz AA, et al. Exploring the validity and reliability of a questionnaire for evaluating virtual patient design with a special emphasis on fostering clinical reasoning. Med Teach. 2015;37:775-782.

36. Al-Eraky MM, Donkers J, Wajid G, Van Merrienboer JJ. Faculty development for learning and teaching of medical professionalism. Med Teach. 2015;37(Suppl 1):S40-S46.

37. Kirschner PA, van Merriënboer JJ. Do learners really know best? Urban legends in education Educ Psychol. 2013;48:169-183.

38. Clark RE. Antagonism between achievement and enjoyment in ATI studies. Educ Psychol. 1982;17:92-101.

39. Reeve C. Narrative-based serious games. In: Petrovic O, Brand A, eds. Proceedings of the Serious Games on the Move. Vienna: Springer; 2009:73-89.

40. Laurel BK. Toward the design of a computer-based interactive fantasy system. The Ohio State University, 1986.

41. Huwendiek S, De Leng BA, Zary N, Fischer MR, Ruiz JG, Ellaway R. Towards a typology of virtual patients. Med Teach. 2009;31:743-748.

42. Aronson L. Twelve tips for teaching reflection at all levels of medical education. Med Teach. 2011;33:200-205.

How to cite this article: Marei HF, Al-Eraky MM, Almasoud NN, Donkers J, Van Merrienboer JJG. The use of virtual patient scenarios as a vehicle for teaching professionalism. Eur J Dent Educ. 2018;22:e253-e260. https://doi.org/10.1111/eje.12283 